\title{
A general approach toward building integrated photovoltaic systems and its implementation barriers: A review.
}

\begin{abstract}
Building integrated photovoltaic (BIPV) systems is one of the most promising technologies and has recently experienced extraordinary growth. There is a huge consensus that these advancements lead to novel methods for domestic energy generation. Technical improvements, governmental supportive laws and financial aids are some of the contributors to this development. However, the proportion of solar power production as compared to conventional electricity generation methods is still negligible and needs more dedication. In this study, a large number of previous research works have been reviewed and reasons and solutions for BIPV success or failure are discussed.
\end{abstract}

Keyword: BIPV; Grid-connected photovoltaic systems; Rooftop solar photovoltaic systems; Renewable energy 